\title{
SPECIAL STRUCTURAL FEATURES IN THE AIR-SACS OF BIRDS.
}

MARY J. ROSS.

The general structure of the respiratory apparatus of birds has, from early times, attracted more or less attention. Nearly every phase of the subject, with the exception, perhaps, of the histologic, has been minutely and carefully investigated. Various birds, as the ostrich, eagie, hawk, sparrow, pigeon, canary and chicken have been studied.

It is the purpose of this paper to discuss the histologic structure of the accessory organs of respiration-the air sacs, as found in the chicken. But before doing so it will be advantageous to review briefly certain peculiarities of the respiratory organs that are intimately correlated with these sacs. The work was conducted in the Anatomical Laboratory of Cornell University, under Dr. Hopkins, to whom I am greatly indebted for kindly interest, valuable suggestions and personal assistance.

Some authors have denied to birds the existence of a diaphragm; but, now, though in structure very different from that of the mammal, two are generally conceded, since the discovery of their use. When the body cavity is opened from the ventral side, the viscera of the thorax and abdomen are seen to occupy the median plane. A tightly stretched sheet of fibrous tissue (oblique septum) on either side serves to hold them in place. These fibrous sheets practically divide the body cavity into thorax and abdoman, as does the diaphragm in mammals. Closely adhering to the ventral surface of each lung, and forming with the oblique septum a closed cavity, is another so-called diaphragm (the pulmonary). These diaphragms resemble closely the air-sacs, but examined minutely are found to be of heavier texture and are less transparent. To the diaphragms are 
attached certain respiratory muscles, which move them in such a manner as to cause the lungs and air-sacs to alternately contract and expand.

"The respiratory apparatus presents modifications more remarkable than those of the circulatory', says Milne-Edwards. Connected with the lungs are large membranous sacs, spread throughout the whole body, and extending even to the cavities of the bones. There are nine of these sacs, of which the thorax contains seven-one thoracic, two cervical, two anterior intermediate, two posterior intermediate, while the abdominal cavity contains but the two abdominal sacs, partially held in place by the diaphragms (Fig. 1). These sacs communicate with the lungs by five perforations on the ventral surface of each lung (Fig. 1). It is stated that some sacs have more than one opening into the lung; but in the chickens which I have examined (ten or more) there was but one orifice to each sac, excepting the thoracic, which contains two, one into each lung, thus making five openings on either side (Fig. 1).

All authors, with the exception of Sappey, who in any way mention the inter-communication of the air-reservoirs, do so but to affirm it. Even Wiedersheim states that all, with the exception of the posterior intermediate, may and often do communicate with one another. Yet, notwithstanding these repeated affirmations, there has been no detailed description as to the manner in which they communicate, or at what point this communication occurs. After careful examination the sacs were found to be entirely independent of each other, thus tending to confirm Sappey's statements as to their non-intercommunication.

The lungs of birds contrast strikingly with those of mammals. They are closely attached to the ribs and vertebræ, are very small, semi-elliptical in shape, of a light rosy hue, and in general texture much more fragile than the lungs of mammals. Then, too, they are not divided into distinct lobes as in certain mammals; their lobulated appearance being due simply to the deep indentations of the ribs and transverse processes of the vertebræ. However, the distinguishing characteristic of birds 
lungs lies in the distribution and termination of the air passages within the lung tissue. In mammals the bronchial tubes pass directly centrad, before sending divisions to the periphery of the lung: in birds they are disposed at the periphery then transmit branches centrad. Sappey's work seems to show conclusively that the bronchioles, instead of ending in a series of alveoli as in mammals, anastomose with one another. Thus a continuous aerial network is formed. Yet Parker makes the following statement: "Besides the branches to the air-sacs, the main bronchus gives off secondary bronchi, and these branch again, sending off tubes, which end blindiy near the surface of the lung and give off blind dilations commonly known as alveoli". In my work on the chicken it was found that if the mesobronchium (Fig. 1, M) be opened and an injection made through the first entobronchium $(\mathrm{G})$ the injection mass penetrates rapidly into the cervical sac (Ar). But almost simultaneously it returns to the mesobronchium through the second and third entobronchia. The liquid reentering the mesobronchium does not nearly equal in amount that which passes to the cervical sac. But if the pressure is continuous the liquid circles around in a constant stream. Some of the liquid also penetrates to the other air chambers. Unless there is anastomosis of the bronchioles it does not appear possible for this to take place. Another experiment that was tried to demonstrate the bronchial anastomosis, requiring much greater care than the one just mentioned, is as follows: The lung of a freshly killed chicken was exposed by removing the surrounding viscera, as the heart, lungs, etc. The pulmonary blood-vessels were tied and all orifices into the air-sacs closed. This latter may be done either by tying or, more easily, by plugging them with cotton. Colored collodion mass was then injected through the main bronchial tube. As soon as this mass becomes somewhat hardened the lung was carefully removed and placed in artificial gastric juice until all of the lung tissue is digested out. The course of the bronchioles can then be traced more readily than in the fresh tissue. However, this method is not entirely satisfactory as the very small 
branches are easily torn, and the connection is thus apt to be lost. Yet enough may be traced to prove that branches from one main bronchial tube anastomose with those from another. In such a preparation as this, the courses of the main branches are clearly shown; how that on leaving the mesobronchium they pass to the dorsal and ventral surfaces, completely covering them with their ramifications. They then pass to the centre, dividing into minute bronchioles, connected with each other. With the exception of the anastomosing bronchioles, the histologic structure of the lungs resembles that of mammals. The air-sacs are thin, transparent membranes, with a more or less fibrous connective tissue basement. Guillot aptly compares them to soap-bubbles. And, when inflated they do resemble large soap-bubbles-slightly glistening, easily destroyed.

All the sacs, with the exception of the thoracic (Fig. 1, T) can be freed from their connections with the adjacent tissue. But there is a close adherence of the thoracic sac to the walls of the thorax. This sac may be distinguished from the rest in having membranous folds partitioning its cavity. Every organ traversing it is completely ensheathed by these folds and so held in place. It extends around the articulation of the shoulder, as the axillary sac, and into the cavity of the humerus (Fig. 1, Ax, H). There were two cases in which the humerus was not pneumatic, and in no case where the femurs were examined were they hollow.

Stricker in his Manual of Histology asserts that the epithelial lining of the sacs is pavement, and that cilia are present in the sacs only near their connections with the lungs. As regards the general character of the epithelium this statement is correct. If a section be taken of any portion of the sacs not attached to the walls of the body the epithelium is pavement. But in a section taken from near the connection of the sacs with the lungs, the epithelium as it leaves the bronchial tubes becomes columnar, gradually changing to pavement epithelium. If the epithelium is stained with silver nitrate the outlines of the cells are brought out distinctly. For this surface-view of the cells 
it is better to examine a two or three days old chick. Here there is no need of a stain. The cells are pentangular, with round nuclei (Fig. 5). If examined while fresh they appear granular and exhibit cilia in motion. Where the membranous sacs are attached to the surrounding tissue a change in the character of the epithelium is apparent. Take for example a section of the small muscle which passes through the thoracic sac, from either side of the trachea to the body wall. Upon examination we find the epithelium to vary greatly. Flattened, $i$ e pavement, cuboidal and columnar cells are all present in the same section (Figs. 2, 3,4). This variation might possibly be ascribed to muscular contraction; however, at the juncture of the muscle and body wall adipose tissue was present in all the specimens examined. Here again where no muscular contraction was possible the same cell changes were noted. Sections of blood-vessels, both veins and arteries, and of muscle from the wall of the thorax also exhibit the same variations in cell outline. There was also noticed a slight difference in the length of the cilia, that on the columnar cells being the longest (Fig. 2).

Stricker's statement as to the presence of cilia is only partially correct. Cilia are present near the connections of the sacs with the lungs, as he says. But they are also present over the entire surface of the sacs contained within the body cavity. Fresh tissue taken from the dorsal as well as from the ventral surface, from the farthest extremity of the abdominal sacs, as well as from near the connection with the lung, exhibits rapidly moving cilia. Various parts of all nine sacs were examined with the same result; cilia were found everywhere. Although the epithelium of each of the nine thoracic and abdominal sacs is ciliated, as just mentioned, repeated examinations failed to disclose any cilia in the evaginations, or prolongations of the thoracic sac around the head of the humerus, (Fig. 1, Ax) and of the abdominal sac around the head of the femur; nor were any found in the cavities of the bones. As the axillary sac (Fig. 1, Ax) is usually of considerable size and in part attached to the muscles of the arm, histologic study of both fresh and 
sectioned tissue is easy. But though several specimens were carefully examined no trace of cilia could be found. The sections were as in Fig. 5 but without cilia. Then the bones were examined, but here again there was no trace of cilia. If the removal of exfoliated epithelium and foreign substances is the principal use of the cilia it is difficult to understand why they are only present in part of the membranous sacs; for the openings from the axillary prolongations, at least, are as large as those from the lung to the thoracic sac (Fig 1, C).

To summarize briefly: The epithelial lining of the membranous sacs is pavement, except where the sac is attached to the surrounding tissue. Here there are variations in the form of the cells, ranging from pavement to columnar epithelial cells. Cilia are present over the entire surface of the sacs contained within the body cavity, but absent from the prolongations of the sacs in the joints and in the cavities of the bones. 


\section{EXPLANATION OF FIGURES.}

All figures are drawn by the aid of a microscope and an Abbé camera lucida, except Fig. 1, which is purely diagrammatic. Figs. 2, 3 and 4 are taken from transections of the muscle connecting the trachea with the body wall, and passing through the thoracic air-sac. The muscle is not drawn in Figs. 2 and 3. 


\section{PLATE I,}

Fig. 1. Diagram to illustrate the relative size, relation, and connection of the lungs and air-sacs.

\section{ABBREVIATIONS.}

A. Orifice from lungs to abdominal sac.

Abd. Abdominal sac.

Ant. I. Anterior intermediate sac.

Ax. Axillary prolongation of thoracic sac.

$B$. Orifice from lungs to posterior intermediate sac.

C. Orifice from lungs to thoracic sac.

Cer. Cervical sac.

$D$. Orifice from lungs to cervical sac.

$E$. Orifice from lungs to anterior intermediate sac.

$F$. Ectobronchia.

Fur. Furcula.

G. Entobronchia.

$H$. Prolongation of axillary sac to the cavity of the humerus.

L. Lungs.

M. Mesobronchium.

Post. I. Posterior intermediate sac.

$T$. Thoracic sac.

Tr. Trachea. 


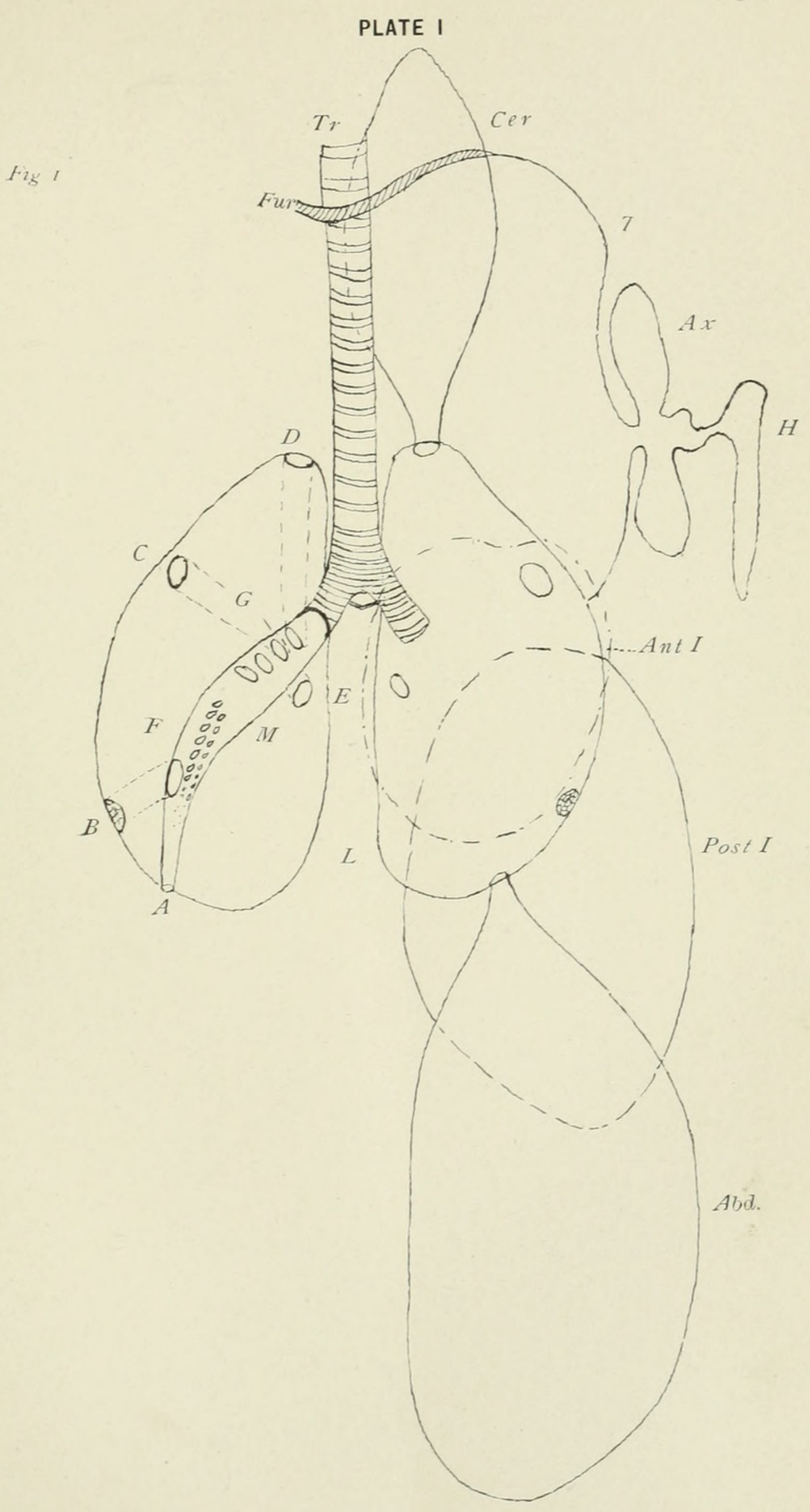






\section{PLATE II.}

Fig. 2. Transection of muscle surrounded by the thoracic sac, showingciliated columnar epithelium, $(\mathrm{Col}$.) with basement membrane of fibrous connective tissue $(\mathrm{Bm}$.)

Fig. 3. Ciliated cuboidal epithelium, $(C u b$. $)$ with basement membrane $(B m$. 


\section{$2 \mathrm{BHL}$ Biodiversity Heritage Library}

Ross, Mary J. 1898. "Special Structural Features in the Air-Sacs of Birds." Transactions 20, 29-40.

View This Item Online: https://www.biodiversitylibrary.org/item/86839

Permalink: https://www.biodiversitylibrary.org/partpdf/90930

\section{Holding Institution}

University of Toronto - Gerstein Science Information Centre

\section{Sponsored by}

University of Toronto

\section{Copyright \& Reuse}

Copyright Status: Not provided. Contact Holding Institution to verify copyright status.

This document was created from content at the Biodiversity Heritage Library, the world's largest open access digital library for biodiversity literature and archives. Visit BHL at https://www.biodiversitylibrary.org. 